\title{
BUBBLE DEPARTURE IN FORCED CONVECTIVE SUBCOOLED BOILING FLOW
}

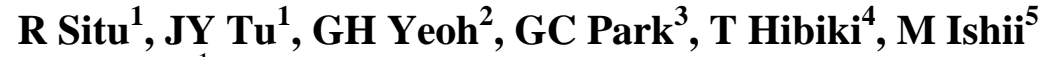 \\ ${ }^{1}$ RMIT University, Bundoora, Australia \\ ${ }^{2}$ Australian Nuclear Science and Technology, Sydney, Australia \\ ${ }^{3}$ Seoul National University, Seoul, Korea \\ ${ }^{4}$ Kyoto University, Kumatori, Japan \\ ${ }^{5}$ Purdue University, West Lafayette, USA
}

\begin{abstract}
Forced convective subcooled boiling flow experiments were conducted in a BWR-scaled vertical upward annular channel. Water was used as the testing fluid, and the tests were performed at atmospheric pressure. A high-speed digital video camera was applied to capture the dynamics of the bubble nucleation process. Bubble departure frequencies were obtained from the video for a total of 92 test conditions. The departure frequency increases as the increase of inlet temperature or heat flux, or the decrease of inlet fluid velocity. A force balance analysis of a growing bubble was performed to predict the bubble departure size to be around $10^{-4} \mathrm{~m}$. The departure frequency is modelled by taking account of transient heat conduction and bubble growth rate. Comparison with experiments suggests that departure frequency falls into two regions: subcooled region and saturate region. The proposed bubble departure frequency model agreed fairly well with the experimental data.
\end{abstract}

$C_{p} \quad$ specific heat at constant pressure

$D_{d}$ bubble departure diameter

$f_{d} \quad$ bubble departure frequency

$F_{b}$ buoyancy force

$F_{d u} \quad$ unsteady drag force (growth force)

$F_{g}$ gravity force

$F_{p}$ pressure force

$F_{q s} \quad$ quasi-steady force

$F_{s} \quad$ surface tension force

$F_{s l} \quad$ shear lift force

$H$ bubble height

$i_{f g} \quad$ heat of vaporization (latent heat)

Ja Jacob number

$k \quad$ thermal conductivity

$q^{\prime \prime} \quad$ heat flux

$R \quad$ intermediate variable

Re Reynolds number

$r_{b}$ bubble radius

$r_{c} \quad$ cavity radius

$\dot{r}_{b} \quad$ derivative of bubble radius with respect to time

$\ddot{r}_{b} \quad$ second derivative of bubble radius with respect to time

$T$ temperature

\section{Nomenclature}

$T_{0} \quad$ wall surface temperature during bubble growth period

$T_{i}(t)$ instantaneous wall surface temperature

$t_{g} \quad$ growth time

$t_{w} \quad$ waiting time

$V_{b}$ bubble volume

$V_{f} \quad$ volume of virtual added mass

$v_{b x} \quad$ bubble front velocity on $x$-direction

$v_{f}$ area-averaged liquid velocity

$v_{f g} \quad$ volume difference between liquid and gas phases

$x \quad$ coordinate

$z \quad$ axial coordinate

Greek symbols

$\alpha$ thermal diffusivity

$\Delta T_{\text {sat }}$ wall superheat

$\delta$ thermal layer thickness

$v \quad$ kinematic viscosity

$\theta_{a}$ advancing contact angle

$\theta_{i}$ inclination angle

$\theta_{r} \quad$ receding contact angle

$\rho$ density

$\sigma \quad$ surface tension 


\begin{tabular}{ll}
\multicolumn{2}{l}{ Subscripts } \\
$\infty$ & infinity \\
$\mathrm{b}$ & bulk \\
$c$ & cavity \\
$d$ & departure \\
$f$ & liquid phase \\
fin & liquid at inlet
\end{tabular}

$\begin{array}{ll}g & \text { vapor phase } \\ i & \text { interface } \\ \text { in } & \text { inlet } \\ \text { sat } & \text { saturation } \\ w & \text { wall } \\ x & x \text {-direction }\end{array}$

\section{Introduction}

The capability to predict two-phase flow behaviours in forced convective subcooled boiling flow is of considerable interest to boiling water reactor (BWR) safety. Currently, the two-fluid model (1975) together with the interfacial area transport equation (1995) can potentially offer an advanced and accurate analysis of thermal-hydraulic characteristics for nuclear reactor systems. Furthermore, to apply the interfacial area transport equation to subcooled boiling conditions, several parameters such as nucleation number density, bubble lift-off size and bubble lift-off frequency are required as the boundary conditions.

The concept of bubble lift-off, i.e., bubble detaching from the heater surface, is different from that of bubble departure, i.e., bubbles detaching from the nucleation site. An active nucleation site in upward forced-convection subcooled boiling is shown schematically in Figure 1. At first, a bubble is nucleated at the nucleation site, and then it gradually grows. After reaching a certain size, it departs from the nucleation site. After departure, the bubble may slide on the heater surface. Then, vaporization occurs at the inner surface of the bubble, while condensation takes place at the outer surface if the tip of the bubbles is out of the superheated layer. Whether the bubble will eventually grow or be condensed is governed by the overall effect of these two processes. However, at some distance downstream of the nucleation site, the bubble eventually lifts off from the heater surface.

The bubble departure phenomena in pool boiling have been extensively studied since 1950s. Zuber (1959) found that bubble departure and the flow regimes are similar to the formation of gas bubbles at orifices. According to Zuber (1964), three regimes of vapor bubble departure from the nucleation site can be discerned: (1) Laminar regime: When vapour flow rates are very low, bubbles rise at a constant velocity, and do not interact with each other. The bubble diameter is almost independent of vapor flow rate, and the bubble departure frequency increases with increasing vapor flow rate. This regime is also referred as the region of static, separated or isolated bubbles. (2) Turbulent regime: When vapour flow rates are intermediate, the bubble departure diameter increases with flow rate while bubble departure frequency remains constant. A bubble interacts and may coalesce with its predecessor above the nucleation site, and the bubble size is non-uniform. This regime is also referred as the region of multiple or interfering bubbles. (3) When vapor flow rates are even higher, a swirling vapor stream is generated at the nucleation site. The vapor jet is similar to a tornado or a waterspout. In our experiments, the bubble departure phenomena in subcooled boiling condition fall in the laminar and turbulent regimes.

In most of the existing efforts to model the bubble departure size in convective flow, a force balance analysis of a bubble was carried out at the instant of departure. Levy (1967)

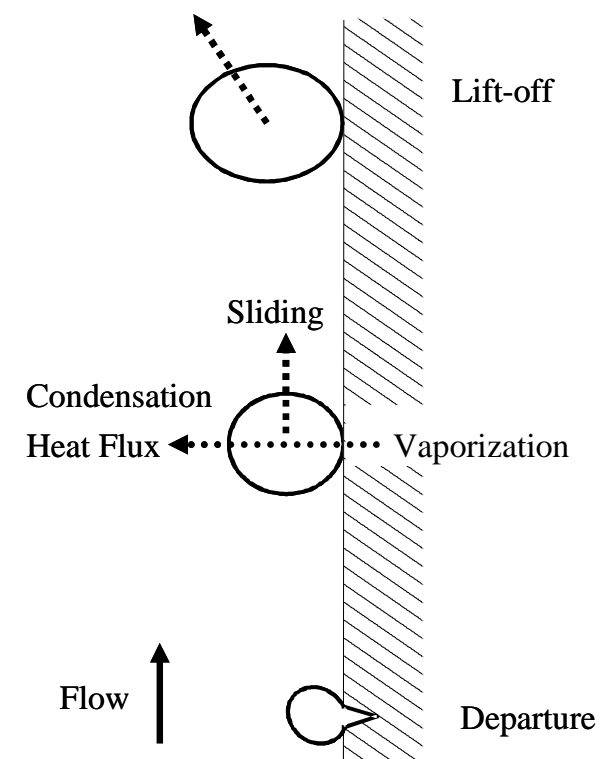

Figure 1. Schematic diagram of bubble nucleation phenomenon. 
postulated that the point of bubble departure was determined from the force balance on a bubble at its nucleation site and the single-phase liquid turbulent temperature distribution away from the heated wall. In his force balance equation, the buoyancy force and wall shear force was assumed to detach the bubble, while surface tension force was to hold it on the wall. He derived a nondimensional equation for the bubble distance from the bubble tip to the wall, which is related to bubble departure size. Staub (1968) considered several different forces acting on a nucleating bubble, including surface tension, momentum change of the liquid due to the growth of the bubble, liquid inertia force, evaporation vapour thrust force, buoyancy force, and drag force. He then assumed that the surface tension, buoyancy, and drag forces were the dominant forces. In his model, the force balance is analysed on a layer of hemispherical bubble, while in Levy's model it was made on a spherical bubble. Al-Hayes and Winterton (1981) modified the friction term of Levy's model to be a drag force in modelling the bubble departure size. Their bubble departure size model was adopted later in Rogers et al. model (1987), where they postulated that the friction factor, heat transfer coefficient, velocity profile and temperature profile at the bubble departure point could be determined from the relationships established for a smooth surface, and the bubble shape was assumed to be distorted by buoyancy and drag force. Kandlikar and Stumm (1994) divided a bubble into the front and the rear regions as two control volumes, and performed force balance analysis on both volumes. Several forces such as surface tension, buoyancy, drag, pressure difference and momentum changes were taken into account. Zeng et al. (1993) studied the forces acting on a bubble in saturated horizontal forced convection boiling. At the point of bubble departure, several forces such as surface tension, hydrodynamic pressure force, and contact pressure force were neglected because the bubble contact area on the wall was approximated to be zero. The bubble departure diameter was modelled based on the simplified force balance equation.

Literature review shows that bubble departure frequency at pool boiling have been broadly studied. Jokob (1949) found that the product of bubble departure frequency and departure diameter to be a constant. Zuber (1963) correlate proposed it as

$$
D_{d} \cdot f_{d}=\frac{1.18}{2}\left[\frac{\sigma g\left(\rho_{f}-\rho_{g}\right)}{\rho_{f}^{2}}\right]^{1 / 4} .
$$

Ivey (1967) offered three correlations with the product of departure frequency and different power of departure diameter for three regions: (1) hydrodynamic region in which buoyancy and drag forces predominate; (2) transition region where buoyancy, drag, and surface tension forces are in the same order; and (3) thermodynamic region where bubble growth dominates.

In literature, researchers attempted to mechanistically model the bubble departure frequency. The first step is to divide the reciprocal of departure frequency, i.e., one nucleation cycle, into two parts. In one nucleation cycle, there exists a waiting time, i.e., $t_{w}$, defined as the period from the moment of the former bubble departs to the moment of the current bubble nucleates, and a growth time, $t_{g}$, which is defined as the period from the moment of bubble appearance until the moment of bubble departure:

$$
f_{d}=\frac{1}{t_{w}+t_{g}} .
$$

Based on the criterion of bubble nucleation and potential flow theory, Han and Griffith (1965) proposed that the waiting time to be the heating time needed for the thermal layer thickness equivalent with $3 / 2$ times of the cavity diameter

$$
t_{w}=\frac{\delta^{2}}{\pi \alpha_{f}}=\frac{9}{4 \pi \alpha_{f}}\left\{\frac{\left(T_{w}-T_{\infty}\right) r_{c}}{T_{w}-T_{s a t}\left[1+\left(2 \sigma / r_{c} \rho_{g} i_{f g}\right)\right]}\right\} .
$$

Hatton and Hall (1966) also proposed model by taking account of the heat storage effect of the heating surface. 
Recently, several investigations have been performed for the bubble departure frequency in convective boiling. Basu et al. (2005) measured both the waiting time and the growth time. The waiting time was correlated wall superheat and the growth time was correlated with bulk subcooling, bubble departure diameter, and superheated liquid layer. Podowski et al. (1997) proposed a mechanistic model of bubble waiting time and growth time. However, the model was not directly validated.

The purpose of this research is to study the bubble departure diameter and frequency in vertical upward forced-convective subcooling boiling flow. Since bubble departure diameter has been studied more extensively, we will emphasize more on bubble departure frequency. The investigation will be carried out in both theoretical and experimental aspects.

\section{Modelling of Bubble Departure Frequency}

\subsection{Modeling of Bubble Waiting Time}

Podowski et al. (1997) propose a mechanistic model of bubble departure frequency for forced convection subcooled boiling. An analytical solution of bubble waiting time was obtained by balancing transient heat transfer in the heated wall and from the wall to the liquid. The onedimensional heat conduction inside the heated wall is given by

$$
\begin{aligned}
& \frac{\partial T_{w}}{\partial t}=\alpha_{w} \frac{\partial^{2} T_{w}}{\partial x^{2}}, \\
& T_{w}(x, 0)=T_{0}+\frac{q_{w}^{\prime \prime}}{k_{w}} x, \\
& T_{w}(0, t)=T_{i}(t),
\end{aligned}
$$

where $T_{0}$ is the wall surface temperature during bubble growth period.

The assumptions are:

1. One-dimensional heat conduction (semi-infinite plate)

2. Linear initial quasi-stationary temperature profile across the wall

3. Steady state wall heat flux

The solution is

$$
T_{w}(x, t)=T_{0}+\frac{q_{w}^{\prime \prime}}{k_{w}} x+\hat{T}_{w}(x, t)
$$

where

$$
\hat{T}_{w}(x, t)=\frac{\alpha_{w}}{2 \sqrt{\pi}} \int_{0}^{t} \frac{x}{\left[\alpha_{w}\left(t-t^{\prime}\right)\right]^{3 / 2}} e^{\frac{-x^{2}}{4 \alpha_{w}\left(t-t^{\prime}\right)}}\left[T_{i}\left(t^{\prime}\right)-T_{0}\right] d t^{\prime}
$$

Similarly, the heat transfer from the wall to the liquid is expressed as

$$
\begin{aligned}
& \frac{\partial T_{f}}{\partial t}=\alpha_{l} \frac{\partial^{2} T_{f}}{\partial x^{2}}, \\
& T_{f}(x, 0)=T_{b}, \\
& T_{f}(-\infty, t)=T_{b}, \\
& T_{f}(0, t)=T_{i}(t),
\end{aligned}
$$

where $x<0$, and $T_{b}$ is the liquid bulk temperature. The solution is 


$$
T_{f}(x, t)-T_{b}=\frac{\alpha_{f}}{2 \sqrt{\pi}} \int_{0}^{t} \frac{x}{\left[\alpha_{f}\left(t-t^{\prime}\right)\right]^{3 / 2}} e^{\frac{-x^{2}}{4 \alpha_{l}\left(t-t^{\prime}\right)}}\left[T_{i}\left(t^{\prime}\right)-T_{b}\right] d t^{\prime} .
$$

By equating the heat fluxes on both sides of the heated wall, the instantaneous wall surface temperature at time $0^{+}$can be expressed as

$$
T_{i}\left(0^{+}\right)=\left(\frac{k_{w} T_{0}}{\sqrt{\alpha_{w}}}+\frac{k_{f} T_{b}}{\sqrt{\alpha_{f}}}\right) /\left(\frac{k_{w}}{\sqrt{\alpha_{w}}}+\frac{k_{f}}{\sqrt{\alpha_{f}}}\right),
$$

and the wall surface temperature at time $t$ becomes

$$
T_{i}(t)=T_{i}\left(0^{+}\right)+\frac{2 q_{w}^{\prime \prime}}{R \pi} \sqrt{t}, \text { and } R=\frac{k_{w}}{\sqrt{\pi \alpha_{w}}}+\frac{k_{f}}{\sqrt{\pi \alpha_{f}}} .
$$

From the nucleation criterion

$$
T_{l}\left(r_{c}, t_{w}\right)=T_{s a t}+\frac{2 \sigma}{r_{c}} \frac{T_{s a t} v_{f g}}{i_{f g}},
$$

the waiting time $t_{\mathrm{w}}$ must satisfy

$$
T_{s a t}+\frac{2 \sigma}{r_{c}} \frac{T_{s a t} v_{f g}}{i_{f g}}=T_{i}\left(t_{w}\right)-\frac{\left\lfloor T_{i}\left(0^{+}\right)-T_{b} \mid r_{c}\right.}{\sqrt{\pi \alpha_{f} t_{w}}}-\frac{q_{w}^{\prime \prime} r_{c}}{R \sqrt{\pi \alpha_{f}}} .
$$

\subsection{Modelling of Bubble Departure Diameter}

To calculate the bubble growth time, the bubble departure diameter should first be obtained. The forces acting on a bubble at its nucleation site are schematically shown in Figure 2 . The forces can be projected into $x$ - and $y$-directions and are given as

$$
\begin{aligned}
& \sum F_{x}=F_{s x}+F_{d u x}+F_{s l}=\rho_{g} V_{b} \frac{d v_{g x}}{d t}, \\
& \sum F_{y}=F_{s y}+F_{d u y}+F_{p}+F_{g}+F_{q s}=\rho_{g} V_{b} \frac{d v_{g y}}{d t},
\end{aligned}
$$

where $F_{s x}, F_{d u x}, F_{s l}, V_{b}, v_{g x}, F_{s y}, F_{d u y}, F_{p}, F_{g}, F_{q s}$ and $v_{g y}$ are the surface tension force at $x$-direction, the unsteady drag force (growth force) at $x$-direction, the shear lift force, bubble volume, bubble velocity at $x$-direction, the surface tension force at $y$-direction, the unsteady drag force at $y$-direction, the pressure force, the gravity force, the quasi-steady force, and the bubble velocity at $y$-direction respectively. In Figure 2, there is an inclination angle, $\theta_{i}(i=a$ : advancing contact angle; $r$ : receding contact angle) between the line from nucleation site to the bubble center and $x$-direction. The surface tension force and unsteady drag forces are projected into $x$ - and $y$-directions as well.

Different from the bubble lift-off, the bubble departs when it violates the force balance along the flow direction. At the moment of bubble departure, the surface tension force can be neglected because the bubble contact area on the wall becomes zero.

The growth force is also called unsteady drag force. For a spherical bubble attached to a wall, the virtual added mass, $V_{f}$, is given by Chen (2003) as

$$
V_{f}=\frac{11}{12} \pi r_{b}^{3} \text {, }
$$

where $r_{b}$ is bubble radius. The growth force can be deemed as the inertial force of this added mass:

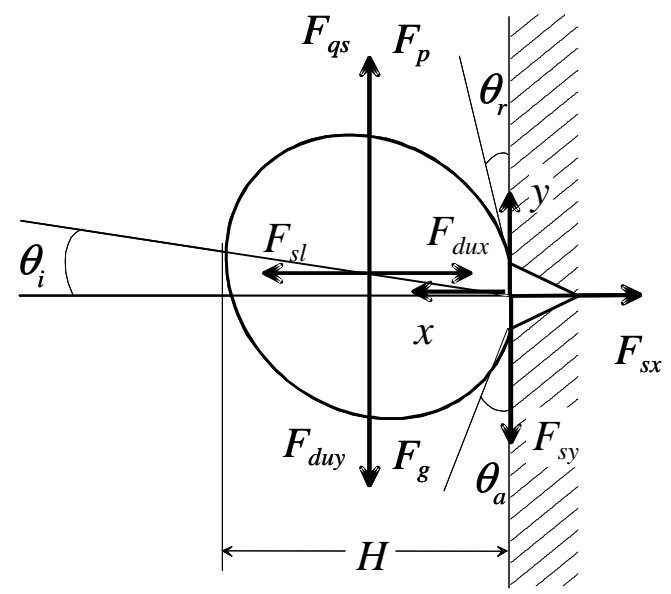

Figure 2. Force balance on a vapour bubble at a nucleate site 


$$
F_{d u}=\frac{d\left(\rho_{f} V_{f} v_{b x}\right)}{d t}=\rho_{f}\left(V_{f} \frac{d^{2} H}{d t^{2}}+\frac{d H}{d t} \frac{d V_{f}}{d t}\right),
$$

where $H$ is the bubble height measured from the wall, and $v_{b x}$ is the bubble front velocity on $x$ direction $v_{b x}=d H / d t$. For spherical bubble, $H$ is the bubble diameter. Thus, $v_{b x}=2 d r_{b} / d t$. Thus from Equations (20) and (21), the growth force is expressed as

$$
F_{d u}=-\rho_{f} \pi r_{b}^{2}\left(\frac{11}{2} \dot{r}_{b}^{2}+\frac{11}{6} r_{b} \ddot{r}_{b}\right),
$$

where $\dot{r}_{b}$ is the derivative of the bubble radius with respect to time, $\ddot{r}_{b}$ is the second derivative of the bubble radius with respect to time. The growth force in and $y$-directions can be expressed by considering the inclination angle $\theta_{i}$ as

$$
F_{d u y}=F_{d u} \sin \theta_{i},
$$

where the inclination angle is set as $\pi / 18$ (Klausner et al. 1993).

The pressure force and the gravity force on a bubble by the surrounding liquid are expressed as

$$
F_{p}=\rho_{f} g V_{b}, F_{g}=-\rho_{g} g V_{b}
$$

where $V_{b}$ is the bubble volume.

For the quasi-steady drag force, Klausner et al. (1993) modified the expression by Mei and Klausner (1992) by taking into account the effect of the wall as

$$
\frac{F_{q s}}{6 \pi \rho_{f} \nu_{f} u_{r} r_{b}}=\frac{2}{3}+\left[\left(\frac{12}{\operatorname{Re}_{b}}\right)^{n}+0.796^{n}\right]^{-1 / n},
$$

where $n=0.65$.

\subsection{Modeling of Bubble Growth Time}

The bubble growth time is calculated from the appearance of bubble to the bubble departure. Bubble's growth depends on the temperature of the liquid surrounding the bubble. Zuber's bubble growth model (1961) agrees fairly well with flow boiling bubble growth data in literature. Its equation is given as

$$
r_{b}=\frac{2 b}{\sqrt{\pi}} \mathrm{Ja} \sqrt{\alpha_{f} t}
$$

where $b$ is a constant suggested as 1.73 by Zeng et al. (1993), and $\alpha_{f}$ is the thermal diffusivity. The Jacob number is defined as

$$
\mathrm{Ja}=\frac{\rho_{f} C_{p f} \Delta T_{s a t}}{\rho_{g} i_{f g}}=\frac{\rho_{f} C_{p f}\left(T_{w}-T_{s a t}\right)}{\rho_{g} i_{f g}},
$$

where $C_{p f}, \Delta T_{s a t}, i_{f g}, T_{w}$ and $T_{s a t}$ are, respectively, the specific heat at constant pressure, the wall superheat, the latent heat, the wall temperature, and the saturation temperature.

\section{Experiments}

\subsection{Experimental facility}

An experimental facility has been designed to measure the relevant two-phase parameters necessary for developing constitutive models for the two-fluid model in subcooled boiling flow. The experimental facility is a scaled-down loop from a prototypic BWR based on proper scaling criteria for geometric, hydrodynamic, and thermal similarities (Rong et al. 2004; 2005). The schematic 
diagram of the flow loop is shown in Figure 3. The subcooled water is held in the main tank. The main tank has a cartridge heater and heat exchanger to control the test-section-inlet subcooling. The water is pumped by a positive displacement pump and divided into four separate is an annulus formed by a clear polycarbonate tube on the outside with an ID of $38.1 \mathrm{~mm}$, and a cartridge heater on the inside with an OD of 19.1 $\mathrm{mm}$. Thus, the hydraulic equivalent diameter is $19.1 \mathrm{~mm}$. The heater has an overall length of $2,670 \mathrm{~mm}$ with a heated section of $1,730 \mathrm{~mm}$ in length. The distance between the test section inlet and the heating section inlet is $212 \mathrm{~mm}$. The maximum power of the heater is $20 \mathrm{~kW}$ that corresponds to a maximum heat flux of 0.193 $\mathrm{MW} / \mathrm{m}^{2}$. At the top of the test section, an expansion joint is installed to accommodate the thermal expansion of the polycarbonate test section. A separation tank is used to separate vapor phase from water. The steam is then condensed, and the water is returned to the main tank. The separation tank is located directly above the main tank. The detailed description of the experimental facility is found in our previous papers (Rong et al. 2004; 2005).

\subsection{Experimental setup of flow visualization}

The setup of the flow visualization system (Rong et al. 2004) is described in Figure 4. A CCD camera is mounted on the back of a magnification-changeable bellow with a $\mathrm{C}$-mount,

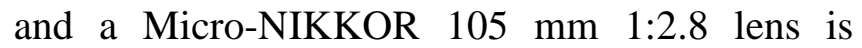
mounted in front of the bellow. The camera is placed on a 1-D traverse rail that can be moved

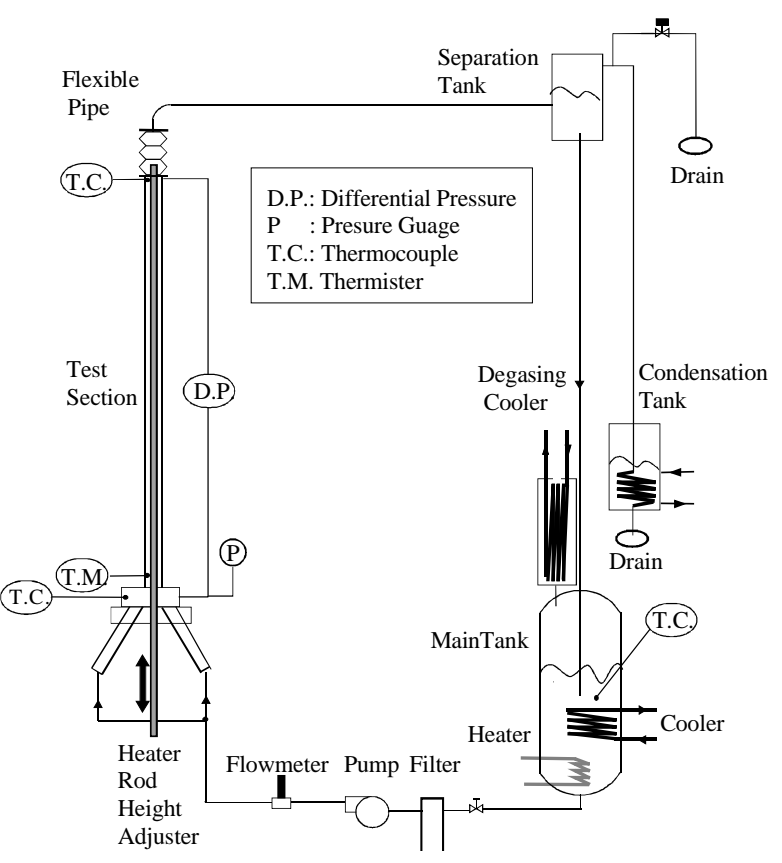

Figure 3. Experimental loop.

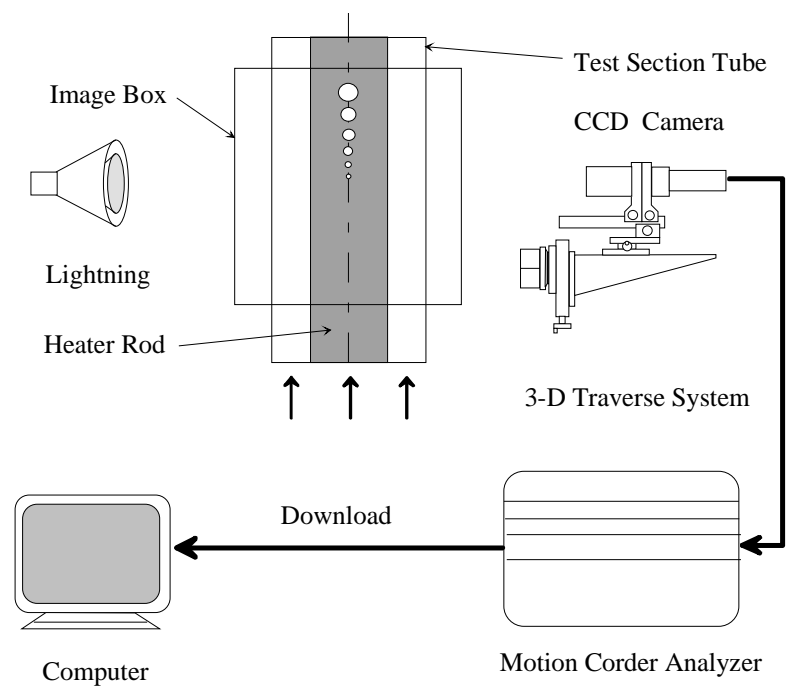

Figure 4. Experimental setup. forward or backward relative to the test section in a certain range. The 1-D traverse rail is placed on a 2-D traverse system that can be moved vertically $(5.0 \mathrm{~cm})$ and laterally $(11.4 \mathrm{~cm})$. This forms a 3-D traverse system. An image box is installed on the test section to minimize the image distortion since the front side of the image box (close to the camera) is filled with water. The side surface of the image box is covered by black paper to avoid any sidelight. Two $300 \mathrm{~W}$ GE spotlights, supported by adjustable arms, are located behind the image box to provide lighting for the flow visualization.

In preparing for an experiment, the water in the main tank was degassed by heating up the tank for 24 hours. Before the measurement, the flow reached steady state, and the inlet temperature and fluid velocity kept constant for 30 minutes. The high-speed video camera was adjusted to focus on an active nucleation site. In order to capture the very short bubble-growth period, i.e., only a few milliseconds, the camera frame rate was set as high as 5,000 frame/second (fps), and the resolution of each image was $80 \times 120$ pixels, which corresponds to a $1.3 \times 2.1 \mathrm{~mm}$ window in reality. The distance between adjacent pixels is $16 \mu \mathrm{m}$. The shutter speed is $1 / 20,000$ second. By adjusting the magnification ratio of the camera, a whole nucleation site along with a certain downstream distance 
can be covered. For each recording, a total of 13,104 frames of pictures, i.e. 2.6 seconds' images, were taken by the video camera and downloaded to a computer. In general, one recording was made for each flow condition in the current experiments.

A MATLAB program has been developed to analyse the digital images and to calculate the bubble diameter when a bubble is attached on the heater rod or in the bulk liquid. The images were calibrated by taking photos of a set of stainless tubes with known diameters. The error caused by the light distortion is significantly reduced by adding the image box. The measurement error of bubble diameter can be estimated as the pixel distance, i.e., $16 \mu \mathrm{m}$.

\subsection{Experimental conditions}

Experiments of 92 conditions were performed for the study of the bubble lift-off size though flow visualization. The inlet temperature ranges from 80.0 to $98.5^{\circ} \mathrm{C}$; the inlet velocity varies from 0.487 to $0.939 \mathrm{~m} / \mathrm{s}$; and the heat flux changes from 60.7 to $206 \mathrm{~kW} / \mathrm{m}^{2}$. In the table, $z_{d}$ represents the distance between the beginning location of the heated section and a specific nucleation site, where the bubble departure frequency, $f_{d}$, are measured. At every steady-state experimental condition, the heater power, inlet water temperature, and inlet water velocity were chosen in such a way that a stable active nucleation site is observed and could be captured by the high-speed video camera.

The inlet temperature was measured by the thermistor probe with interchangeable sensor accuracy of $\pm 0.1{ }^{\circ} \mathrm{C}$. The pressure drop cross the test section is measured by Honeywell ST 3000 Smart Transmitter. The combined zero and span inaccuracy for the differential pressure cell is $\pm 0.4 \%$ of span. Heat flux and inlet velocity were acquired by a data acquisition system. The measurement accuracies of heat flux, liquid temperature, liquid velocity, pressure, and differential pressure are \pm 1 $\%, \pm 0.1{ }^{\circ} \mathrm{C}, \pm 1 \%, \pm 1 \%$ full-scale reading $(55 \mathrm{kPa})$, and $\pm 1 \%$ full-scale reading $(6.9 \mathrm{kPa})$, respectively.

After the measurement at one flow condition were finished, the next condition was reached either by adjusting the heat flux, for example, Tests 1 to 6 , or by changing the inlet temperature, for instance, Tests 7 to 9 . In Table 1, the adjacent rows with the same $z_{d}$ refer to the same nucleation site.

\subsection{Experimental results and discussion}

Figure 5 shows the bubble departure frequency against the inlet temperature for one nucleation site at $z_{d}=1.13 \mathrm{~m}$. It suggests that the bubble departure frequency increases as the inlet temperature increases. The effect of the heat flux can also be found in this figure. The data indicated by $\mathrm{O}, \Delta$, and $\square$, have similar inlet fluid velocity but different heat flux. The figure indicates that the solid curve (linear fit of the $\mathrm{O}$ data, $\left.q^{\prime \prime}=202 \mathrm{~kW} / \mathrm{m}^{2}\right)$ is higher than the broken curve (linear fit of the $\square$ data, with $q^{\prime \prime}=146$ $\mathrm{kW} / \mathrm{m}^{2}$ ), and the broken curve is higher than the $\square$ data (with $q^{\prime \prime}=101 \mathrm{~kW} / \mathrm{m}^{2}$ ). The effect of fluid velocity is suggested by comparing the $\square$ and $\nabla$ data. Assuming the dependence of the $\square$ and $\nabla$ data on the inlet temperature are similar to the solid and broken curves in the figure, the curve

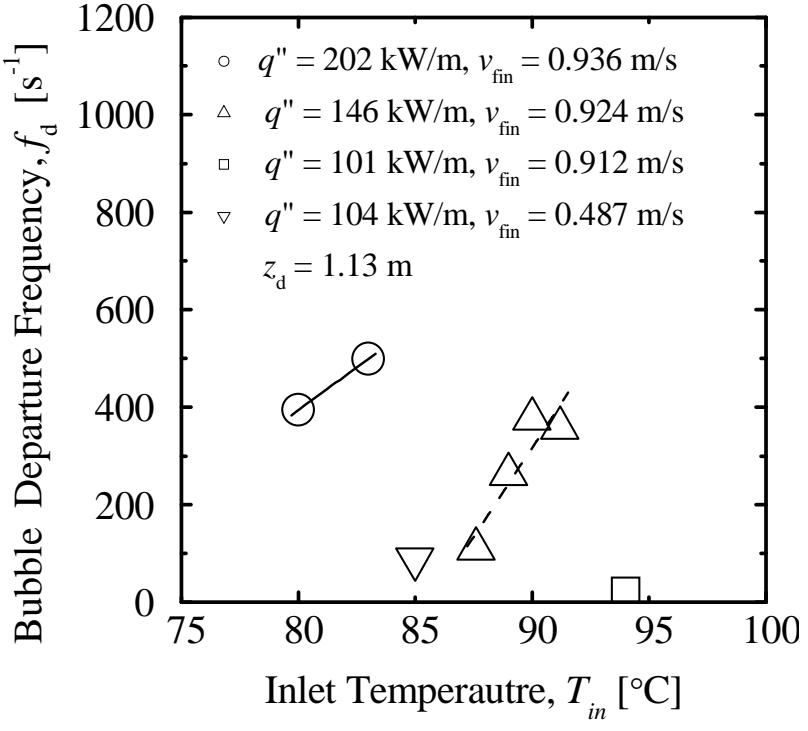

Figure 5. Dependence of bubble departure frequency on inlet temperature at $z_{d}=1.13 \mathrm{~m}$. 
with lower fluid velocity $\left(\nabla, v_{\text {fin }}=0.487 \mathrm{~m} / \mathrm{s}\right)$ would be higher than that with higher inlet fluid velocity $\left(\square, v_{\text {fin }}=0.912 \mathrm{~m} / \mathrm{s}\right)$. Higher inlet temperature, higher heat flux, or lower fluid velocity would result in higher wall temperature at the nucleation site, and thus higher bubble departure frequency.

Figure 6 shows the measured bubble departure frequency against the inlet temperature. The figure indicates that the bubble departure frequency increases as the inlet temperature increases. Because nucleation sites are captured at different axial positions, and have different cavity sizes, it is rather difficult to compare the bubble departure frequencies among different nucleation sites.

Since bubble slides immediately after departure from the nucleation site, it is difficult to capture the bubble at the moment of departure. Images from experiment confirm that the departure diameter is round $10^{-4} \mathrm{~m}$. Accurate measurement of bubble departure frequency require higher camera frame rate and higher resolution in future study.
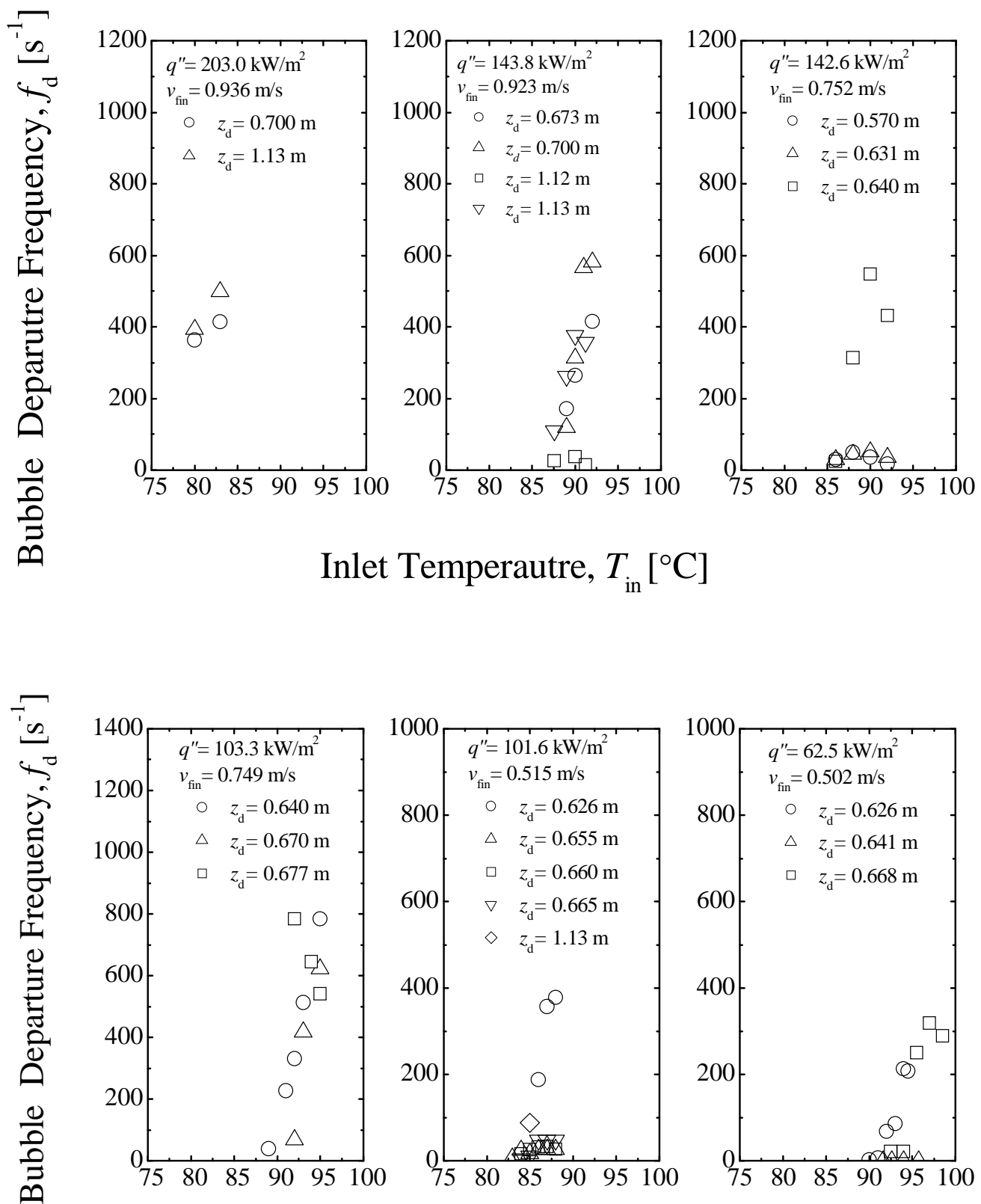

Inlet Temperature, $T_{\text {in }}\left[{ }^{\circ} \mathrm{C}\right]$

Figure 6. Dependence of bubble departure frequency on inlet temperature. 


\subsection{Comparison of model with experimental data}

The models introduced above are attempted to predict bubble departure diameter and frequency. The wall surface temperature is calculated by Chen's correlation (1966). The results indicated that the predicted bubble waiting times are in the order of $0.01 \mathrm{~s}$, while the bubble growth time has an averaged value at $0.14 \mathrm{~ms}$, which agrees well with experimental observation. However, the model under-predicts when the bubble departure frequency is higher than $100 \mathrm{~Hz}$. In practical cases, when one bubble departs from the cavity, the bubble size is in the order of $0.1 \mathrm{~mm}$. The surrounding liquid might be at saturation temperature, or even higher. Thus the assumption in Equation (10) might not sound reasonable. Experiments indicate that the departure frequency is very sensitive to the thermal layer at the nucleation site. Furthermore, previous paper (Rong et al. 2004) also suggests that two different nucleation phenomena exist. For departure frequencies less than $200 \mathrm{~Hz}$, the waiting time is relatively apparent and longer, while for frequencies higher than $300 \mathrm{~Hz}$, the waiting times are negligible. This can be explained as follows: for the first case, just after one bubble departs from the cavity, the surround water temperature is lower than the temperature required for nucleation; while for the later case, it is the opposite. Thus, we classify the experiment data into two regions: (1) for departure frequency less than $100 \mathrm{~Hz}$, the instantaneous wall surface temperature at time $0^{+}, T_{i}\left(0^{+}\right)$, at Equation (14), is modified as

$$
T_{i}\left(0^{+}\right)=\left(\frac{k_{w} T_{0}}{\sqrt{\alpha_{w}}}+\frac{k_{f} T_{s a t}}{\sqrt{\alpha_{f}}}\right) /\left(\frac{k_{w}}{\sqrt{\alpha_{w}}}+\frac{k_{f}}{\sqrt{\alpha_{f}}}\right) .
$$

(2) For departure frequency higher than $100 \mathrm{~Hz}$, the superheat close to the wall is so high that the flow in the whole channel can be assumed to be saturate flow, and the instantaneous wall surface temperature can be deems as a constant value, i.e. $\mathrm{T}_{0}$. Thus Eq. (17) becomes

$$
T_{s a t}+\frac{2 \sigma}{r_{c}} \frac{T_{s a t} v_{f g}}{i_{f g}}=T_{i}\left(t_{w}\right)-\frac{\left[T_{0}-T_{s a t}\right] r_{c}}{\sqrt{\pi \alpha_{f} t}}-\frac{q_{w}^{\prime \prime} r_{c}}{R \sqrt{\pi \alpha_{f}}} .
$$

Furthermore, the cavity radius is set as $10^{-5} \mathrm{~m}$ in Podowski's model. Experiments findings indicate that the cavity size varies significantly, and it might have a strong influence on the departure frequency. The relationship between $r_{c}$ and $T_{i}\left(0^{+}\right)$is

$$
\begin{aligned}
& T_{s a t}+\frac{2 \sigma}{r_{c}} \frac{T_{s a t} v_{f g}}{i_{f g}}=T_{i}\left(0^{+}\right)-\frac{q_{w}^{\prime \prime} r_{c}}{R \sqrt{\pi \alpha_{f}}} \\
& r_{c}=\frac{-A_{2} \pm \sqrt{A_{2}^{2}-4 A_{1} A_{3}}}{2 A_{1}}
\end{aligned}
$$

where $\quad A_{1}=\frac{q_{w}^{\prime \prime}}{R \sqrt{\pi \alpha_{f}}} \quad, \quad A_{2}=T_{\text {sat }}-T_{i}\left(0^{+}\right)$, $A_{3}=\frac{2 \sigma T_{s a t} v_{f g}}{i_{f g}}$. The minimum values of $r_{c}$ is adopted since they better fit with the experiment.

Figure 7 plots the predicted departure frequency with experimental data. The averaged error is $68.7 \%$. Although fairly good agreement is achieved, the boundary between these two regions has not been predicted due to the limitation of the experimental data. The wall temperature is obtained from correlation rather than from measurement (Rong et al. 2005). This causes some error to the prediction. For future investigations, the saturate

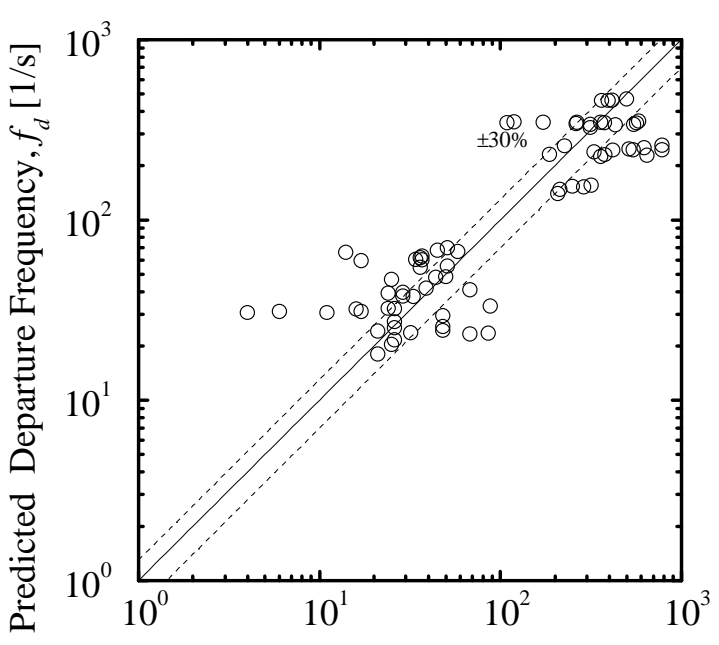

Experimental Departure Frequency, $f_{d}[1 / \mathrm{s}]$

Figure 7. Comparison between predicted and measured bubble departure frequency 
thermal layer should also be studied experimentally and theoretically, and it will improve the model dramatically.

The model in section 2.2 predicts the bubble departure diameter in the order of $10^{-4} \mathrm{~m}$, which agrees well with experimental findings. Thus it is proposed that the force balance analysis of bubble departure diameter can offer reasonable result, and the quantitative benchmark require further study.

\section{Conclusions}

Forced convective subcooled flow boiling experiments were conducted in a BWR-scaled verticalupward annular channel by using water as testing fluid. The test runs were performed at atmosphere pressure. The inlet temperature ranged from 80.0 to $98.5^{\circ} \mathrm{C}$; the inlet velocity varied from 0.487 to $0.939 \mathrm{~m} / \mathrm{s}$; and the heat flux changed from 60.7 to $206 \mathrm{~kW} / \mathrm{m}^{2}$. A high-speed digital video camera was used to capture the dynamics of the subcooled nucleation process. Bubble departure frequencies were obtained from the images for a total of 92 test conditions. The results indicated that bubble departure frequency increases with increasing of the inlet temperature, increasing of the heat flux, or decreasing of the inlet fluid velocity.

The theoretical investigation is conducted. The bubble waiting time is modeled by considering of the transient heat conduction both in the wall and the liquid. The bubble growth time is modeled by calculating bubble departure diameter, which is predicted around $10^{-4} \mathrm{~m}$ by force balance analysis. The predicted bubble waiting time is much higher than the growth time. Comparison with the experiment finds that the departure frequency falls into two regions with $100 \mathrm{~Hz}$ as the boundary. For departure frequency higher than $100 \mathrm{~Hz}$, the flow can be deemed as saturated flow with shorter waiting time; while for frequency lower than $100 \mathrm{~Hz}$, bubble need more waiting time. The proposed model agreed reasonably well with experimental data.

\section{Acknowledgements}

This research project is supported by Australian Research Council (ARC) Discovery Program. The authors would like to express their sincere appreciation for the support from ARC.

\section{References}

R. A. M. Al-Hayes, and R. H. S. Winterton, Bubble diameter of detachment in flowing liquids, International Journal of Heat and Mass Transfer 24(1981) 223-230.

N. Basu, G. R. Warrier, V. K. Dhir, Wall heat flux partitioning during subcooled flow boiling: Part1 - Model development, Journal of Heat Transfer 127 (2005) 131-139.

J. C. Chen, Correlation for boiling heat transfer to saturated fluids in convective flow, I\&EC Process Design and Development 5 (1966) 322-329.

Y. Chen, M. Groll, R. Mertz, and R. Kulenovic, Force analysis for isolated bubbles growing from smooth and evaporator tubes, Transaction of the Institute of Fluid-Flow Machinery 112 (2003) 57-74.

C. Y. Han and P. Griffith, The mechanism of heat transfer in nucleate pool boiling - Part I: Bubble initiation, growth and departure, International Journal of Heat and Mass Transfer 8 (1965) 887904.

A. P. Hatton and I. S. Hall, Photographic study of boiling on prepared surfaces, Third International heat Transfer Conference, 4 (1966) 24-37, August 7-12, 1966, Chicago, Illinois, USA.

M. Ishii, Thermo-fluid dynamics theory and two-phase flow, Eyerolles, Paris, 1975.

H. J. Ivey, Relationships between bubble frequency, departure diameter and rise velocity in nucleate boiling, International Journal of Heat and Mass Transfer 10 (1967) 1023-1040.

M. Jakob, Heat Transfer, Volume 1, Chapter 29, Wiley, New York, 1949. 
S. G. Kandlikar, and B. J. Stumm, A control volume approach for investigating forces on a departing bubble under subcooled flow boiling, Fundamentals of Phase Change: Boiling and Condensation, ASME HTD-Vol. 273 (1994) 73-80.

J. F. Klausner, R. Mei, D. M. Bernhard, and L. Z. Zeng, Vapor bubble departure in forced convection boiling, International Journal of Heat and Mass Transfer 36 (1993) 651-662.

G. Kocamustafaogullari, and M. Ishii, Foundation of the interfacial area transport equation and its closure relations, International Journal of Heat and Mass Transfer 38 (1995) 481-493.

S. Levy, Forced convection subcooled boiling-prediction of vapor volumetric fraction, International Journal of Heat and Mass Transfer 10 (1967) 951-965.

R. Mei, and J. F. Klausner, Unsteady force on a spherical bubble at finite Reynolds number with small fluctuations in the free-stream velocity, Phys. Fluids A 4 (1992) 63-70.

R. M. Podowski, D. A. Drew, R. T. Lahey, Jr., and M. Z. Podowski, A mechanistic model of the ebullition cycle in forced convection subcooled boiling, Proceedings of Eight International Topical Meeting on Nuclear Reactor Thermal-Hydraulics, 3 (1997) 1535- 1542.

J. T. Rogers, M. Salcudean, Z. Abdullah, D. McLeod, and D. Poirier, The onset of significant void in up-flow boiling of water at low pressure and velocities, International Journal of Heat and Mass Transfer 30 (1987) 2247-2260.

R. Situ, Y. Mi, M. Ishii, and M. Mori, Photographic study of bubble behaviours in forced convection subcooled boiling, International Journal of Heat and Mass Transfer 47 (2004) 36593667.

R. Situ, T. Hibiki, M. Ishii, and M. Mori, Bubble lift-off diameter in forced convective subcooled boiling, International Journal of Heat and Mass Transfer 48 (2005) 5536-5548.

F. W. Staub, The void fraction in subcooled boiling - prediction of the initial point of net vapor generation, Journal of Heat Transfer (1968) 151-157.

L. Z. Zeng, J. F. Klausner, D. M. Bernhard, and R. Mei, A unified model for the prediction of bubble detachment diameters in boiling systems - II. Flow boiling, International Journal of Heat and Mass Transfer 36 (1993) 2271-2279.

N. Zuber, Hydrodynamic aspects of boiling heat transfer, U.S. AEC Rep. AECU 4439, Tech. Inf. Serv. Oak Ridge, Tenn. (1959).

N. Zuber, The dynamics of vapor bubbles in nonuniform temperature fields, International Journal of Heat and Mass Transfer 2 (1961) 83-98.

N. Zuber, Nucleate boiling. The region of isolated bubbles and the similarity with natural convection, International Journal of Heat and Mass Transfer 6 (1963) 53-78.

N. Zuber, Recent trends in boiling heat transfer research Part I: Nucleate pool boiling, Applied Mechanics Reviews, 17 (1964) 663-672. 